\title{
Dynamic variation characteristics of layered monitored land subsidence near a fast railway line
}

\author{
Kaiwen Shi ${ }^{1,2,3}$ and Yong Luo $^{4}$ \\ ${ }^{1}$ Key Laboratory of Land Subsidence Monitoring and Prevention, Ministry of Natural Resources of the \\ People's Republic of China, Shanghai, 200072, China \\ ${ }^{2}$ Shanghai Institute of Geological Survey, Shanghai, 200072, China \\ ${ }^{3}$ Shanghai Engineering Research Center of Land Subsidence, Shanghai, 200072, China \\ ${ }^{4}$ Beijing Institute of Geo-Environment Monitoring, Beijing, 100195, China
}

Correspondence: Kaiwen Shi (2694525775@qq.com)

Published: 22 April 2020

\begin{abstract}
The fast railway line B is a high-speed railway passenger passageway in Beijing, with a total length of $40.75 \mathrm{~km}$. In the plain area, the railway passes through the land subsidence area of Beijing from south to north, which poses a certain threat to the normal operation of a high-speed railway. Using layered monitoring data for the period 2009-2014 from station A, this paper analyses dynamic changes in the annual subsidence rate and the rate and percentage of soil deformation at different depths, as well as the compression deformation law of soil with different lithology and depth with the change of the water level. The results show that (1) since 2012, the proportion of shallow-layer $(\leq 82 \mathrm{~m})$ compression and settlement contribution has gradually decreased, while the proportion of deep-layer (> 82 m) compression has significantly increased; (2) during the deformation process of layered soil, the amount of compression is closely related to the change of groundwater level; and (3) the shallow, middle and deep strata show obvious viscoelastic-plastic deformation characteristics on the whole.
\end{abstract}

\section{Introduction}

Beijing is the central and important area for the development of a high-speed railway. In recent years, due to the rapid development of the economy and agricultural construction in Beijing, the demand for groundwater resources has been increasing. Chinese scholars have proposed that with the increase of groundwater exploitation and uneven spatial distribution in Beijing, Beijing has become a region with some of the most severe groundwater pumping worldwide and one of the regions with some of the most severe land subsidence in China (Zhang et al., 2015). The fast railway line B is a highspeed railway passenger passageway in Beijing, with a total length of $40.75 \mathrm{~km}$ (see Fig. 1). In a plain area, the railway passes through the Beijing land subsidence area from south to north, which is affected by land subsidence to a certain extent ( $\mathrm{Li}, 2016)$. Chinese engineers realized that the construction of the fast railway line B will lead to the surge of water demand in the areas along the line, and the situation of set- tlement will be more severe. While the high-speed railway has higher requirements for the control of land subsidence, the contradiction between the two is prominent (Wang et al., 2015). Land subsidence will cause a certain degree of impact and damage to linear engineering such as rail transit and high-speed railway, mainly manifested as structural damage, orbital deformation, etc. (Wang et al., 2014).

Therefore, in order to ensure the safe and reliable development of fast railway line B project's property and facilities, it is necessary to analyse the land subsidence characteristics of the fast railway line B and study the compression contribution value of different layers to land subsidence and the deformation characteristics of the layered soil. 


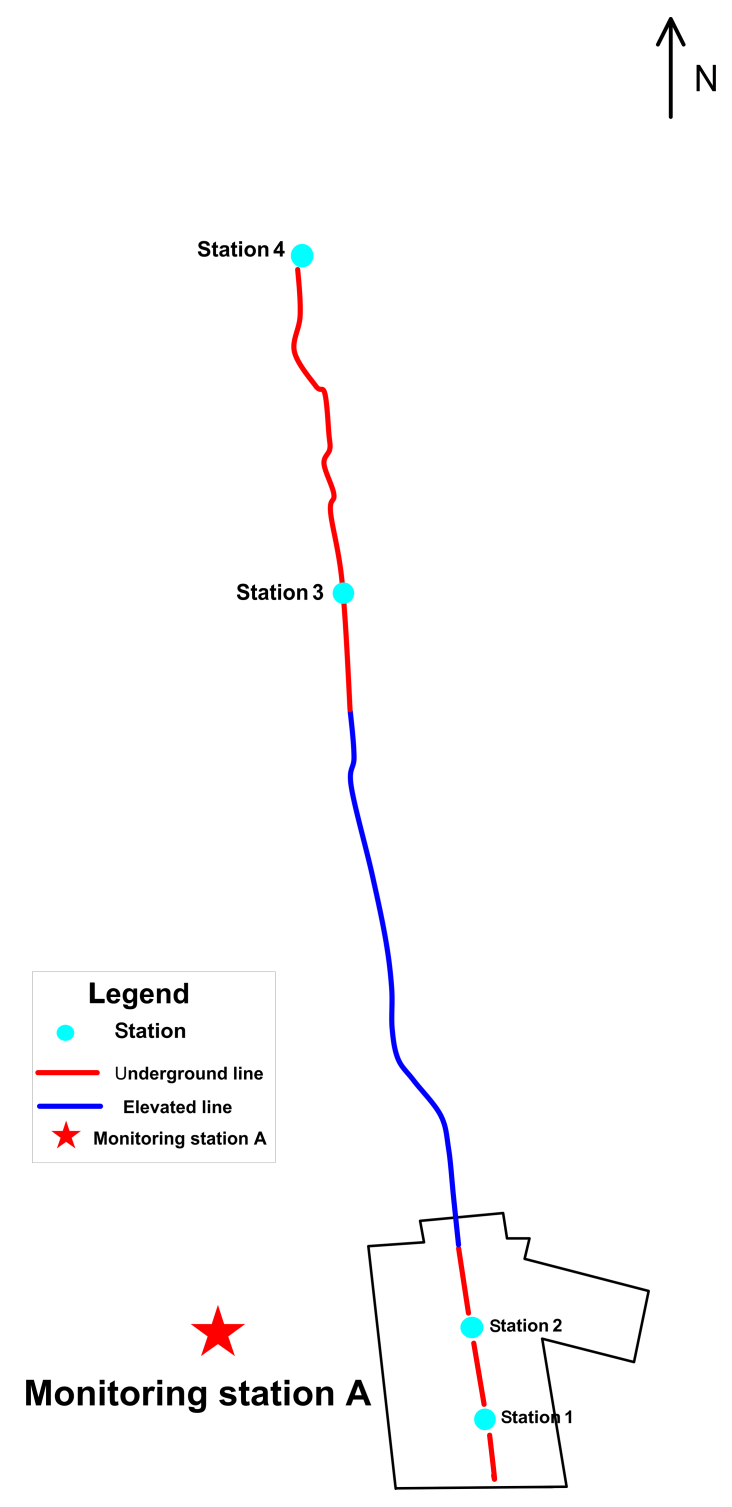

Figure 1. Schematic diagram of the fast railway line B.

\section{Basic situation of the land subsidence monitoring station}

The land subsidence monitoring station A (see Fig. 1) is built along the southwest of the first phase of the fast railway line B. There are one bedrock mark, seven layerwise marks, five groundwater long-term observation wells and two pore water pressure observation wells in the station (Liu et al., 2012). Since the implementation of monitoring on 27 June 2008, the monitoring station has collected a large amount of data about the layered deformation of land subsidence, groundwater level dynamics and pore water pressure through automated data collection, according to which the deformation characteristics of the soil can be analysed. Based on the statistical analysis of the monitoring data of monitoring station

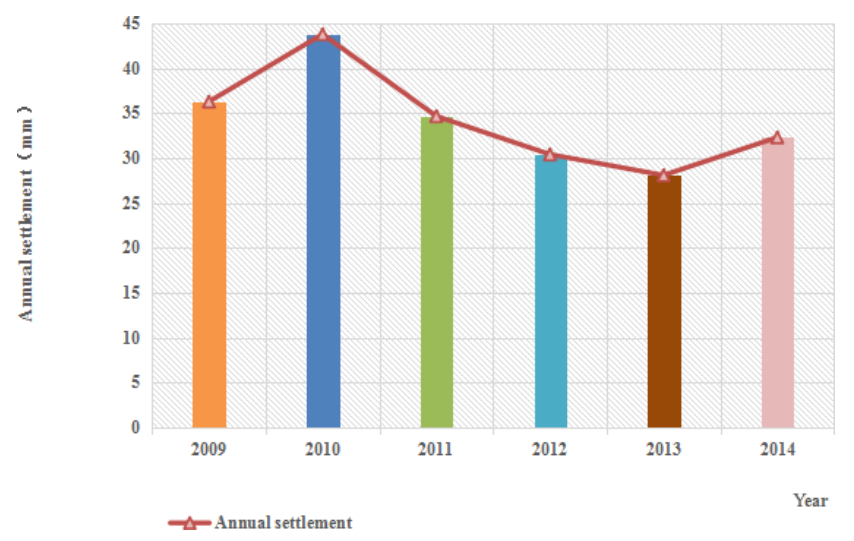

Figure 2. Annual settlement change of station A (2009-2014).

A, this paper reveals the dynamic characteristics of land subsidence in the plane and vertical direction.

\section{Characteristic analysis of land subsidence}

\subsection{Characteristics of annual settlement}

The annual land subsidence of monitoring station A (20092014) is shown in Fig. 2. Combined with the monitoring data results, it can be seen that the annual settlement variation of monitoring station A was relatively stable, with an average annual settlement of $34.25 \mathrm{~mm}$; the fluctuation range was between $28.08-43.78 \mathrm{~mm}$, with a range value of 15.701 , and the standard deviation was only $5.03 \mathrm{~mm}$. It indicated that the land subsidence in the area monitored by the monitoring station A was in a relatively stable state. On the whole, the settlement in the area of station A experienced a fluctuation process of first increasing, then decreasing year by year and finally increasing. Taking 2010-2013 as an example, the annual settlement decreased year by year from $43.781 \mathrm{~mm}$ in 2010 to $28.08 \mathrm{~mm}$ in 2013. The annual settlement in $2014 \mathrm{in}-$ creased by about $4.2 \mathrm{~mm}$ compared with that in 2013 , which may be related to the increase of groundwater mining intensity and depth in this area since 2014.

\subsection{Layered compression characteristics}

According to the monitoring data of the layered standard of the ground subsidence monitoring station A from 2009 to 2014, a curve of the annual settlement of each layerwise mark was made (Figs. 3 and 4) to facilitate the analysis of the deformation characteristics of different depth soil layers. As can be seen from the figure:

1. From 2009 to 2013 , the annual settlement of F7-5, F7-6 and F7-7 layerwise marks decreased year by year. Although the settlement of these three layerwise marks increased somewhat in 2014, the extent of the increase was small. Generally speaking, the annual settlement of 


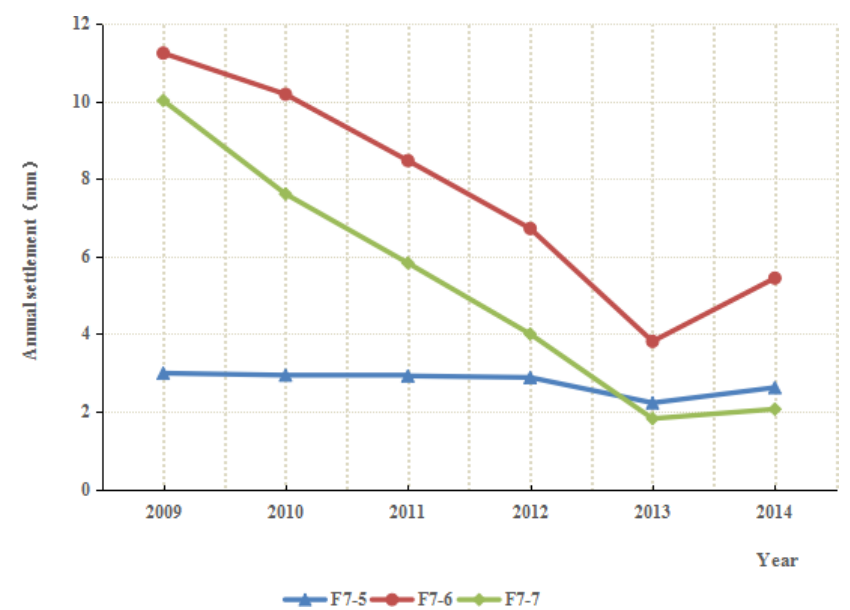

Figure 3. Annual settlement change curve of layerwise marks in the shallow layer (2009-2014).

these three layerwise marks showed a significant downward trend. The corresponding monitoring layers of F75, F7-6 and F7-7 are 53-82, 27-53 and 2-27 m respectively; they are all shallow strata (depth $\leq 82 \mathrm{~m}$ ), indicating that the compression contribution of shallow strata (depth $\leq 82 \mathrm{~m}$ ) decreased year by year in the 6year period.

2. The corresponding monitoring layers of F7-1, F7-2, F73 and F7-4 are 82-116, 116-170, 170-205 and below $205 \mathrm{~m}$ respectively. The F7-1 annual settlement had a large fluctuation within the 6 years, showing a trend of increasing first, then decreasing and then increasing again, indicating that the compressive deformation of the stratum was unstable. Compared with F7-1, the annual settlement trend of F7-2 and F7-4 were similar, and the variation of settlement amount was relatively smooth. The settlement monitored by F7-3 in 2014 reached $8.03 \mathrm{~mm}$, an increase of $4.218 \mathrm{~mm}$ compared with 2009. Taking the settlement of layerwise marks in 2014 as an example, under the condition that the settlement of F7-2 and F7-4 were almost unchanged compared with 2009, the settlement of F7-1 and F7-3 increased by $10.298 \mathrm{~mm}$ in total, while F7-1, F7-2, F73 and F7-4 are all strata with a monitoring depth greater than $82 \mathrm{~m}$, indicating that the total compression contribution of deep strata increased in 2014 .

In order to analyse the variation law of the shallow and deep compression contribution ratio over the years more intuitively, the proportion of compression contribution of different depth layers to the total amount from 2009 to 2014 was concluded and summarized. The detailed rules were shown in Figs. 5 and 6.

From Figs. 5 and 6, it can be seen that before 2012, the monitoring station A was a "subsidence type of the shallow layer". That is to say, the compression deformation mainly

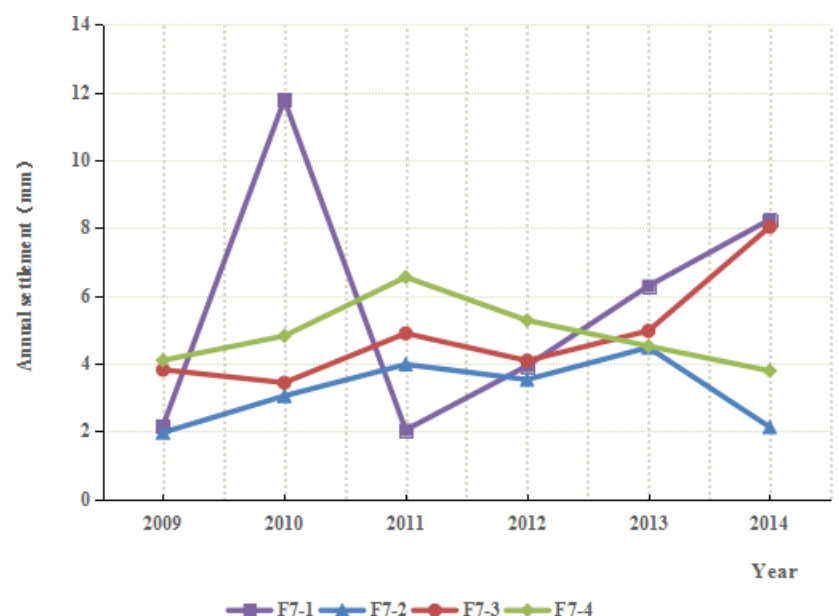

Figure 4. Annual settlement change curve of layerwise marks in the deep layer (2009-2014).

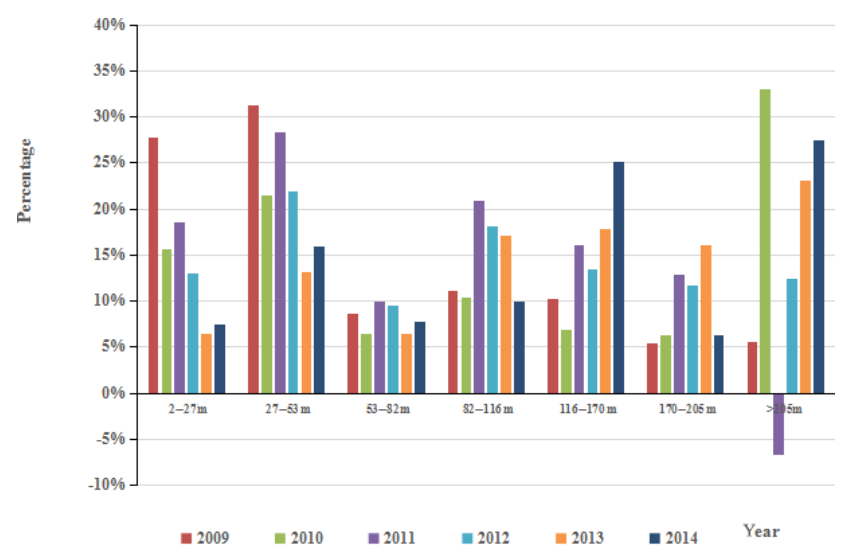

Figure 5. Histogram of the annual layered compression ratio of monitoring station A (2009-2014).

occurred in the shallow part (the depth is not more than $82 \mathrm{~m}$ ). However, in the past 2 years, the compression ratio of the shallow layer has shown a significant decline. The contribution ratio of shallow-layer compression (depth $\leq 82 \mathrm{~m}$ ) has decreased from $67.62 \%$ in 2009 to $25.97 \%$ in 2013, a decrease of $41.65 \%$. This shows that the influence of shallowlayer compression on the total land subsidence was gradually weakening, while the compression ratio of deep layers increased significantly. The compression contribution of a layer with a depth of more than $82 \mathrm{~m}$ was $32.38 \%$ in 2009 and $74.17 \%$ in 2013 , an increase of $41.79 \%$. According to the 2014 data, although the compression ratio of shallow formations has increased compared to 2013, reaching $31.19 \%$, the compression ratio of the deep layer was $68.81 \%$, which still occupies a dominant position, indicating that the contribution ratio of deep-layer compression has increased significantly in recent years. The deep layers are the main compression horizon of land subsidence at present. 


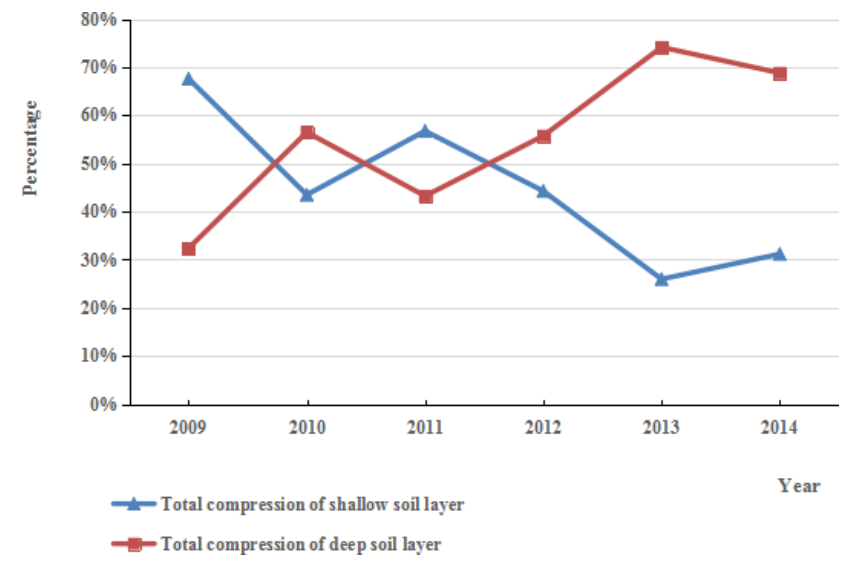

Figure 6. Annual total settlement percentage line chart of the shallow and deep soil layers (2009-2014).

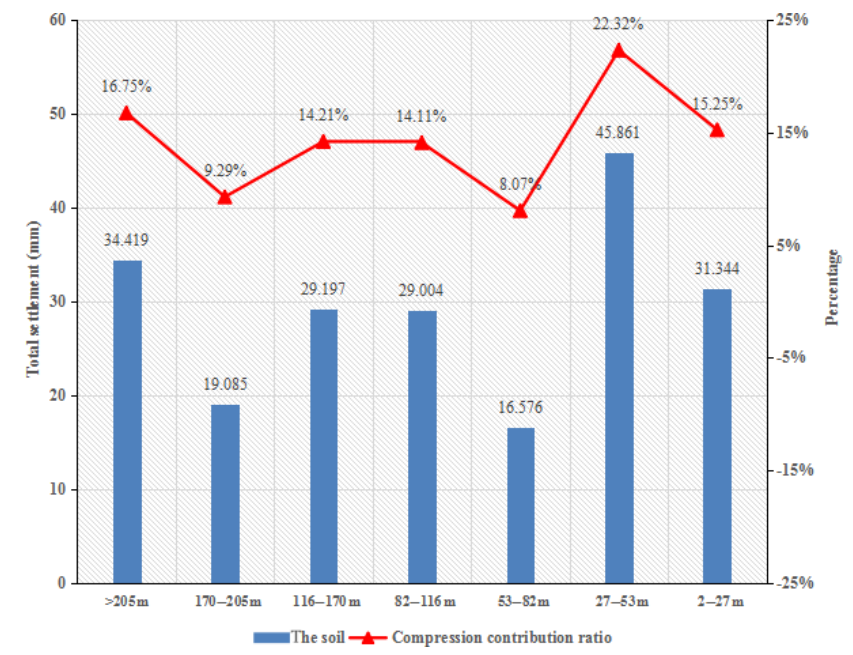

Figure 7. Comprehensive map of the layered compression quantity and compression ratio for monitoring station A (2009-2014).

The monitoring data of station A show that the compression layer of land subsidence was mainly located in the depth range of $27-53 \mathrm{~m}$ and below $205 \mathrm{~m}$ from 2009 to 2014 and that the compression amount accounted for $22.32 \%$ and $16.75 \%$ of the total compression amount of all layers in turn. The compression ratios of the 2-27, 53-82, 82-116, 116170 and $170-205 \mathrm{~m}$ layers were $15.25 \%, 8.07 \%, 14.11 \%$, $14.21 \%$ and $9.29 \%$ respectively, with a small compression gap among different layers (see Fig. 7).

\subsection{Deformation characteristics of layered soil}

By using the monitoring data of the layerwise mark and the corresponding change of the water level to make the stressstrain curve of soil mass, the deformation characteristics of the soil at different depths were analysed. The results show that the soil layers monitored by layerwise marks have a significant viscoelastic-plastic deformation feature.

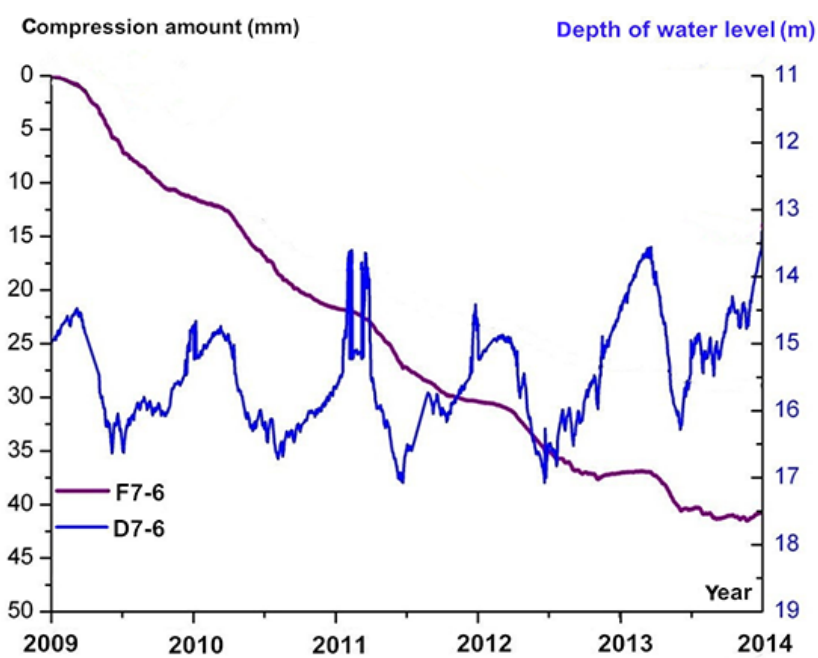

(a) Groundwater level and deformation over time

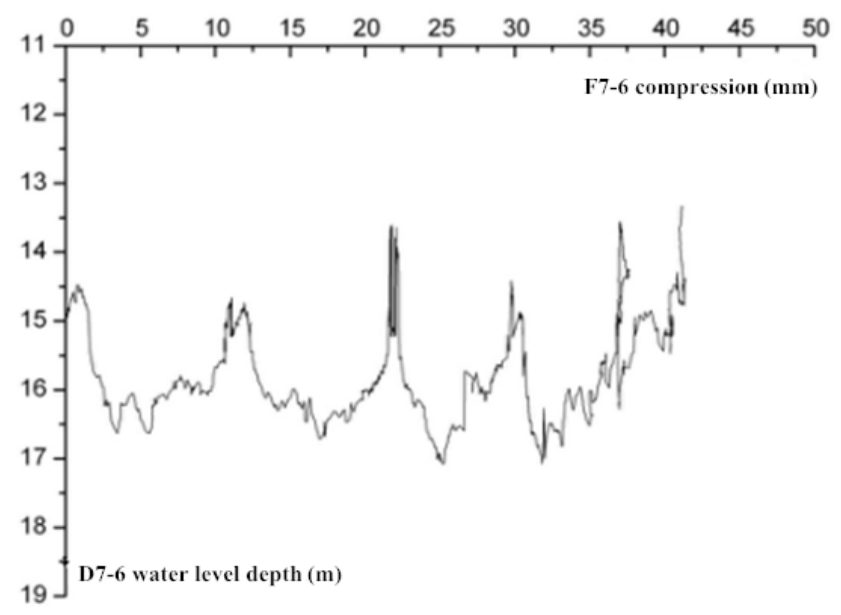

(b) Groundwater level versus deformation

Figure 8. Deformation behaviour of the shallow soil mass in relation to its corresponding groundwater level at layered mark F7-6.

F7-6 is selected as a typical monitoring point in the shallow layer, with a monitoring interval of $27-53 \mathrm{~m}$. F7-3 is selected as a typical monitoring point in the middle layer, with a monitoring interval of 116-170 m. F7-1 is selected as a typical monitoring point in the deep layer, and its monitoring interval is below $205 \mathrm{~m}$. As shown in Figs. 8a, 9a and 10a, the water level rose and fell periodically. Correspondingly, the soil also showed repeated effects of loading and unloading. It can be seen from Figs. $8 \mathrm{~b}, 9 \mathrm{~b}$ and $10 \mathrm{~b}$ that when the water level rose, the soil was still compressed, but the deformation speed was slowed down, and the rebound amount is very small. As the water level rose gradually the amount of compression deformation decreased year by year. Under the circumstance that the shallow underground water level rises slightly and the groundwater level in the middle stratum drops, the soil monitored by the F7-6 and F7-3 not only had plastic deformation with large residual deformation, but 


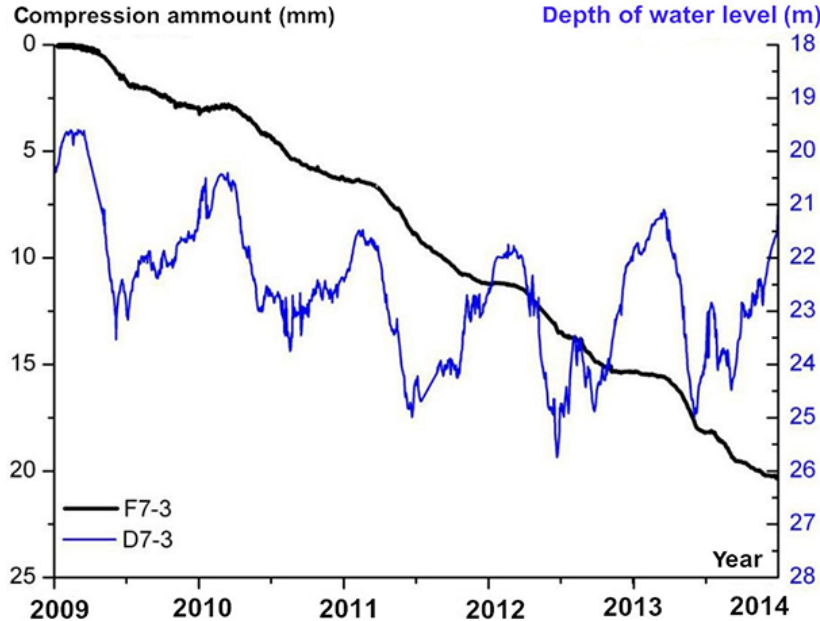

(a) Groundwater level and deformation over time

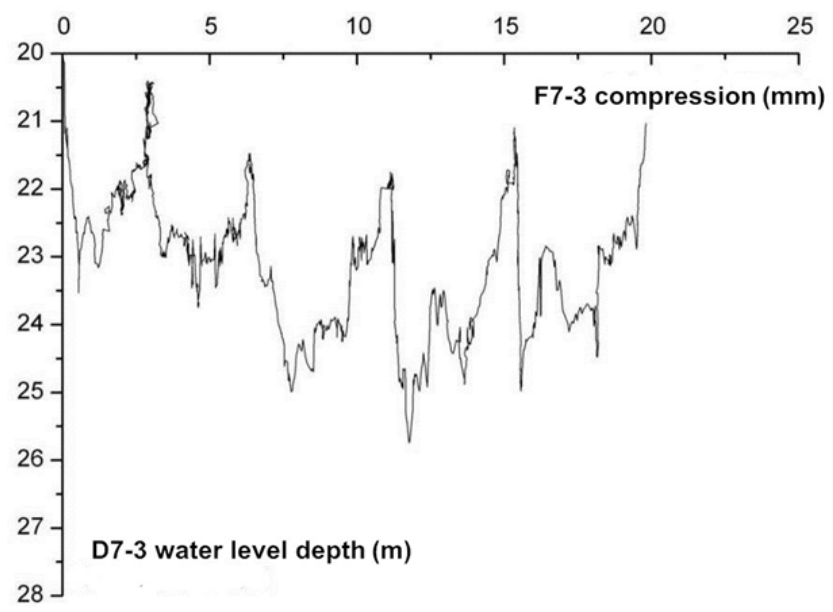

(b) Groundwater level versus deformation

Figure 9. Deformation behaviour of the middle soil mass in relation to its corresponding groundwater level at layered mark F7-3.

it also had creep deformation over time, with significant viscoelasticity and plasticity. It can be seen from Fig. 10b that the curve of F7-1 characterizing the relationship between the water level and deformation shows a hysteresis loop with no complete closure in the period of 2010-2011, showing a certain elastic deformation characteristic. However, with the passage of time and the continuous decline of the water level, the rebound phenomenon began to weaken gradually and showed more and more obvious plastic deformation characteristics and creep deformation with time, which had significant viscoelastic plasticity.

\section{Conclusions}

This paper carries out the analysis of land subsidence characteristics of the fast railway line B. Through the analysis of the stratified monitoring data of land subsidence monitoring station $\mathrm{A}$, the following main conclusions are obtained:

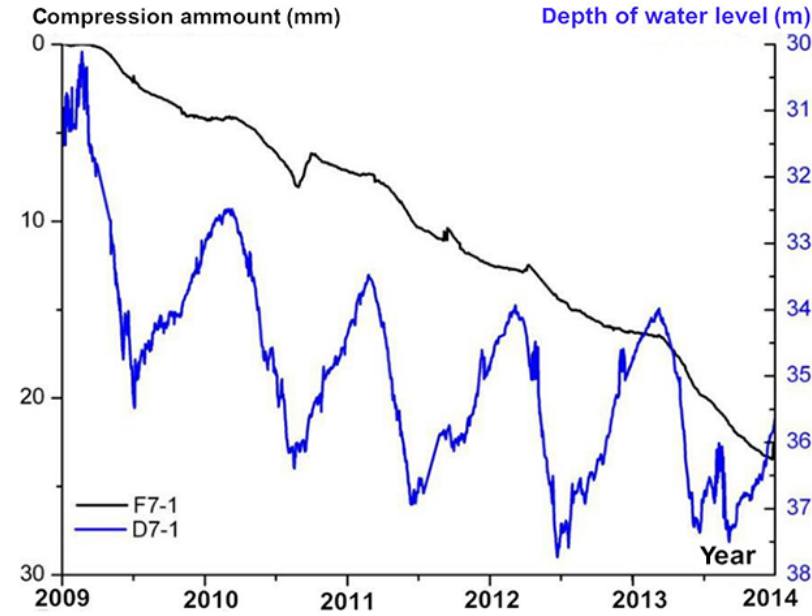

(a) Groundwater level and deformation over time

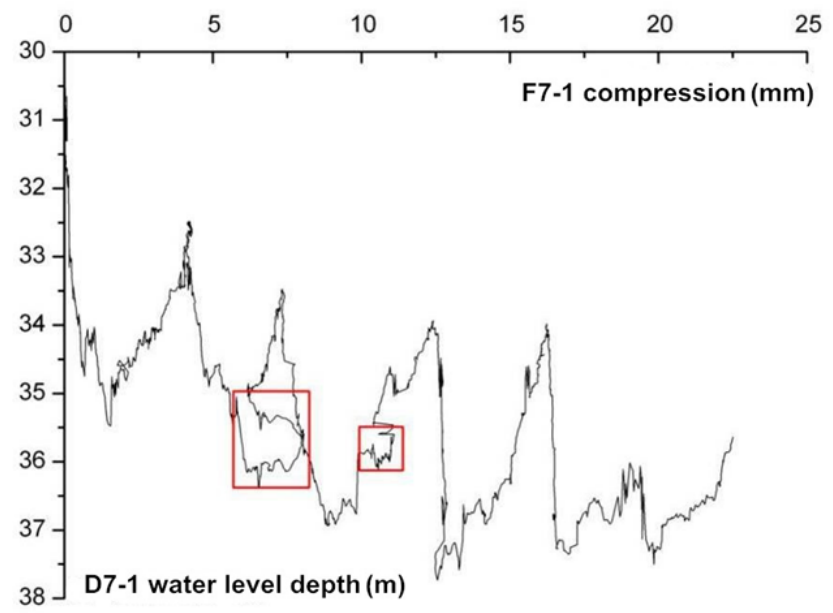

(b) Groundwater level versus deformation

Figure 10. Deformation behaviour of the deep soil mass in relation to its corresponding groundwater level at layered mark F7-1.

1. The stratified compression of land subsidence in the study area presents three distinct features. Firstly, the compression contribution of a layer with depth less than $82 \mathrm{~m}$ was larger; secondly, the compression gap between different depths of the strata was small; and finally, since 2012, the proportion of shallow formation compression and compression contribution has decreased year by year, and the proportion of deep formation compression has increased significantly.

2. On the basis of the elevation of the water level in the shallow strata, there was a slight decrease of the water level in the middle strata and an obvious decrease of the water level in the deep strata, and the soils monitored by the layerwise marks showed significant viscoelasticplastic deformation characteristics. 
3. In the process of layered-soil deformation, the compression amount was closely related to the variation of the groundwater level.

Data availability. All data generated or used during the study appear in the submitted article.

Author contributions. KS performed the formal analysis and writing of the paper. YL provided the monitoring data.

Competing interests. The authors declare that they have no conflict of interest.

Special issue statement. This article is part of the special issue "TISOLS: the Tenth International Symposium On Land Subsidence - living with subsidence". It is a result of the Tenth International Symposium on Land Subsidence, Delft, the Netherlands, 17-21 May 2021.

Acknowledgements. This is a contribution of the IGCP project 663 "Impact, Mechanism, Monitoring of Land Subsidence in Coastal cities" of the IUGS and UNESCO.

Financial support. This research has been supported by the Shanghai Science and Technology Commission (grant no. 18DZ1201100).

\section{References}

Li, F. M.: Regional settlement impact on Urban Rail Transit, Municipal Engineering Technology, 34, 81-84, 2016 (in Chinese with English abstract).

Liu, M. K., Jia, S. M., and Chu, H. L.: The monitoring system and technologies of land subsidence in Beijing, Geol. Resour., 21, 244-249, 2012 (in Chinese with English abstract).

Wang, R., Liu, M. K., Jia, S. M., Yang, Y., Tian, F., and Liu, H. H.: Research based on the high-speed railway affect the dynamic quantitativerelationship between groundwater and land subsidence, Chinese Journal of Geological Hazard and Control, 25, 49-53, 2014 (in Chinese with English abstract).

Wang, R., Luo, Y., Tian, M. Z., Tian, F., Yang, Y., and Liu, H. H.: Study of groundwater development plan based on land subsidence control in Beijing New Airport City, City Geology, 10, 13-17, 2015 (in Chinese with English abstract).

Zhang, W., Gong, H. L., Chen, B. B., and Duan, G. Y.: Evolution and genetic analysis of land subsidence in Beijing Typical Area, Journal of Geo-information Science, 17, 909-916, 2015 (in Chinese with English abstract). 